\title{
8
}
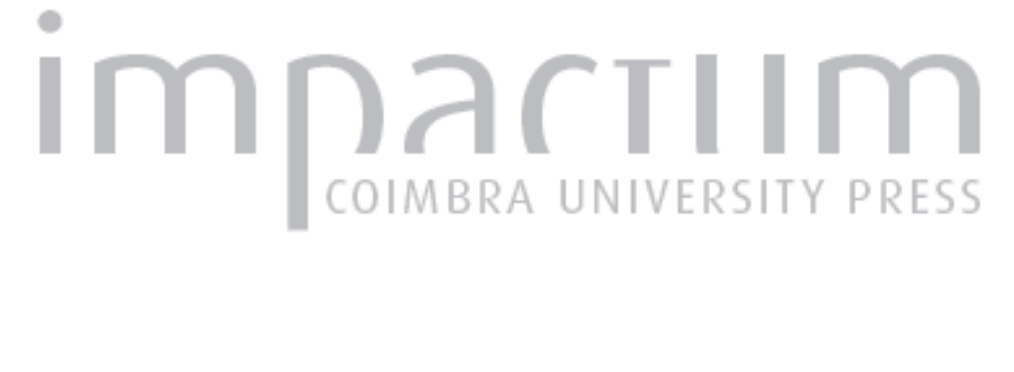

\section{A imagem do Rei na História Genealógica da Casa Real Portuguesa: um estudo preliminar}

Autor(es): $\quad$ Mota, Isabel Maria H. F.

Publicado por: Imprensa da Universidade de Coimbra

URL persistente:

http://hdl.handle.net/10316.2/42912

DOI:

https://doi.org/10.14195/2183-8925_11_5

Accessed : $\quad$ 26-Apr-2023 07:00:14

A navegação consulta e descarregamento dos títulos inseridos nas Bibliotecas Digitais UC Digitalis, UC Pombalina e UC Impactum, pressupõem a aceitação plena e sem reservas dos Termos e Condições de Uso destas Bibliotecas Digitais, disponíveis em https://digitalis.uc.pt/pt-pt/termos.

Conforme exposto nos referidos Termos e Condições de Uso, o descarregamento de títulos de acesso restrito requer uma licença válida de autorização devendo o utilizador aceder ao(s) documento(s) a partir de um endereço de IP da instituição detentora da supramencionada licença.

Ao utilizador é apenas permitido o descarregamento para uso pessoal, pelo que o emprego do(s) título(s) descarregado(s) para outro fim, designadamente comercial, carece de autorização do respetivo autor ou editor da obra.

Na medida em que todas as obras da UC Digitalis se encontram protegidas pelo Código do Direito de Autor e Direitos Conexos e demais legislação aplicável, toda a cópia, parcial ou total, deste documento, nos casos em que é legalmente admitida, deverá conter ou fazer-se acompanhar por este aviso.

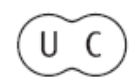


REVISTA DE HISTÓRIA DAS IDEIAS 11

\section{CULTURA POLÍTICA MENTALIDADES}

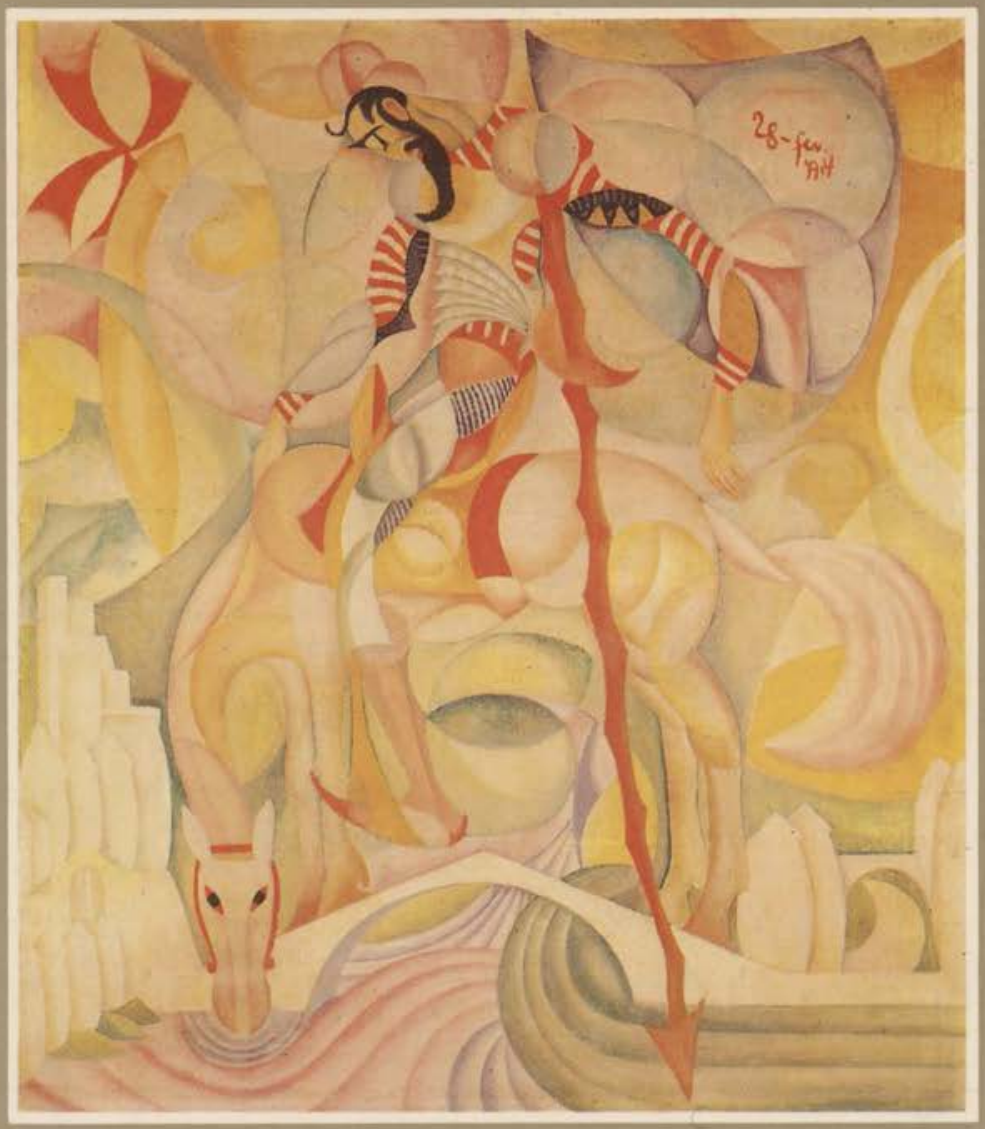

INSTITUTO DE HISTORIA E TEORIA DAS IDEIAS FACULDADE DE LETRAS 


\title{
A IMAGEM DO REI NA HISTÓRIA GENEALÓGICA DA CASA REAL PORTUGUESA
}

\author{
um estudo preliminar **
}

\section{«SENHOR}

....Se V. M. não se conhece.... eu o direi em breves palavras.»

Arte de Furtar

Não tratamos a História Genealógica da Casa Real Portuguesa $\left({ }^{1}\right)$ como uma manifestação de «ideologia». Dispensamo-nos assim de perfilhar a teoria de Maravall que apontaria, por se tratar de uma obra de historiografia barroca, para a sua inclusão num "complexo de interesses monárquico-senhoriais», configurando-a eventualmente como "resposta dada pelos grupos activos» a uma "difícil crise» e reconduzindo-a, no limite, ao estatuto de um exemplo de cultura "dirigida" e "conservadora" $\left({ }^{2}\right)$.

António Caetano de Sousa, membro da Academia Real da História Portuguesa (instituída por D. João V em Decreto de 8 de Dezembro de 1720), não faz uma história (da intervenção) de Deus, não propõe uma Teleologia ou uma Escatologia e embora fale frequentemente da Divina Providência é como um pressuposto mais ou menos distante. A História

* Faculdade de Letras da Universidade de Coimbra.

** Este trabalho é um primeiro passo no tema da tese de dovtoramento que nos propomos realizar: História da História no Século XVIII.

(1) D. António Caetano de Sousa, Historia Genealogica da Casa Real Portugueza, 13 vols., Lisboa, 1735-48, seguida pelas Provas da Historia Genealogica da Casa Real Portugueza Tiradas dos instrumentos dos Archivos, 6 vols., Lisboa, $1739-48$ e pelo Indice Geral, Lisboa, 1749. Utilizámos para consulta a 2.a edição da História Genealógica da Casa Real Portuguesa, revista por M. Lopes de Almeida e César Pegado, 26 vols., Coimbra, Atlântida, 1946-55. Nas citações a actualização da ortografia é da nossa responsabilidade.

(2) Cf. José António Maravall, La cultura del Barroco, Barcelona, Ariel, 1986 (4." edição). 
Genealógica não começa com a Criação do Mundo como a primeira parte da Monarquia Lusitana, começa sim, muito concretamente, com a genealogia do conde D. Henrique: "sexto neto de Roberto I o Forte, Duque, e Marquês de França. em que damos princípio, e assentamos por tronco das Reais Casas de Portugal, França e Castella» $\left({ }^{3}\right)$. Ela também não apresenta nenhuma causalidade final que oriente a acção em geral. Esta ausência total de escatologia ou teleologia não é novidade, ela tinha sido já claramente defendida por D. Francisco Manuel de Melo: «....porque o mundo, se bem é verdade que se há-de acabar, não se há-de desfazer primeiro que se acabe. Com todas suas forças e faculdades se há-de ir à sepultura, e até o fim permanecerá na própria ordem em que começou....; porque tem proporção que, assim como Deus de nada fez tudo, de tudo faça nada; e, como o mundo nunca ascendeu por graus sucessivos à sua perfeição, não desça por outros tais à sua aniquilação» $\left(^{4}\right)$.

$\mathrm{O}$ que de facto António Caetano de Sousa faz é uma Genealogia: abandonou o projecto que the distribuiu a Academia ("Memórias Eclesiásticas Ultramarinas») para se entregar à História Genealógica, Genealogia pela qual esteve sempre e quase exclusivamente interessado. O próprio Conde da Ericeira, membro da Academia Real. o apoia na sua "Censura»: "Estudo era este intrinsecamente necessário...., por ser a Genealogia um dos primeiros elementos da História, tanto para perceber os interesses políticos....; quanto para a ordem Cronológica, não confundindo o tempo....” ( $\left(^{5}\right)$. E a Genealogia que dá ordem aos tempos, por isso a Genealogia é a História. No caos dos pequenos factos, dos fragmentos, Caetano de Sousa introduz a Genealogia como o equilíbrio, o que dá ordem ao mundo o mecanismo do mundo. Para falar de António Caetano de Sousa poderemos apropriar-nos das palavras que Walter Benjamin dedicou à "Contra-Reforma»: "L'jdéal de sa philosophie de l'histoire c'était l'acmé: un âge d'or pour la paix et les arts, libre de tout aspect apocalyptique, conçu et garanti in aetennum....» $\left({ }^{6}\right)$.

(3) D. António Caetano de Sousa, História Genealógica da Casa Real Portuguesa, 2." edição, tomo I, p. 20.

(4) D. Francisco Manuel de Melo, Apólogos Dialogais, Lisboa, Sá da Costa, 1959, vol. II, pp. 101 e 102.

(5) Censura do Conde da Ericeira, Sargento môr de Batalha, e Académico da Academia Real \& C., in António Caetano de Sousa, ob. cit., tomo I.

$\left.{ }^{(}\right)$Walter Benjamin, Origine $d u$ drame baroque allemand, Paris, Flammarion, 1985 (trad. franc., estabelecida a partir da edição das Obras completas de Walter Benjamin em 6 vols., vol. I, 1 , Suhrkamp, 1974), p. 80. 
Por isso "a maior glória dos Reis é a posteridade" $\left({ }^{7}\right)$ (descendência). Idade de ouro é para Caetano de Sousa o reinado de D. João V, sem dúvida, o "felicíssimo reinado", o "mais feliz Império» que ele espera seja garantido in aeternum pela Real Casa Reinante $\left(^{8}\right)$. Mas igualmente o foram o de D. João I ou o de D. João II, o Príncipe Perfeito: «Foi feliz o seu Reinado, pela paz, abundância, e bom governo" $\left({ }^{9}\right)$.

A História de António Caetano de Sousa é construída com um infinito número de pequenos factos apresentados com detalhe e minúcia e sem qualquer fio dominante. A primeira preocupação é o "realismo»: "necessariamente são tantos e tão diversos os documentos de que se teceu a História Genealógica da Casa Real» e "Tudo trato com uma indiferente neutralidade.... e somente com o desejo da verdade.... sigo o verdadeiro, apartando-me do fabuloso. com a autoridade dos autores de maior crédito ou dos documentos com que se acreditam as opiniões para serem verdadeiras" $\left({ }^{10}\right)$. Acrescenta, para tanto. os volumes de Provas da História Genealógica da Casa Real Portuguesa Tiradas dos Instrumentos dos Archivos.

Poderíamos falar (na esteira de Walter Benjamin) num "método infinitesimal» para esta História ${ }^{11}$ ).

Mais uma vez, este realismo não é único nem é novo. Luís Reis Torgal encontra e acentua o realismo e o pragmatismo no pensamento político da Restauração $\left({ }^{12}\right)$ tal como Vítor Manuel de Aguiar e Silva encontra o mesmo realismo na poesia lírica barroca: "apresenta também a poesia barroca um vigoroso pendor para a captação do real, sobretudo do real quotidiano, analisado e figurado, muitas vezes, com a minudência de uma visão míope» $\left({ }^{13}\right)$.

(7) Cf. António Caetano de Sousa, ob. cit., tomo III, p. 283.

(8) Cf. tomo VIII da História Genealógica, "Advertencias, e Addiç̧oens», p. 2: «....Real Casa Reinante, que Deus prospere, e abençoe de sorte, que na diuturnidade do tempo, se dilate a sua Real posteridade, por tão dilatados séculos, que competindo com a duração do mesmo Mundo, seja esta uma das mais esclarecidas Épocas da História Lusitana....».

${ }^{(9)}$ António Caetano de Sousa, ob. cit., tomo III, p. 64.

(10) "Apparato à História Genealogica da Casa Real Portugueza», in António Caetano de Sousa, ob. cit., tomo I, p. X.

(11) Cf. Walter Benjamim, ob. cit., p. 94.

(12) Cf. Luís Reis Torgal, Ideologia Politica e Teoria do Estado na Restauração, 2 vols., Coimbra, Biblioteca Geral da Universidade, 1981 e 1982.

(13) Vítor Manuel de Aguiar e Silva, Maneirismo e Barroco na Poesia Lírica Portuguesa, Centro de Estudos Românicos, Coimbra, 1971, p. 433. 
António Caetano de Sousa não deixa de reafirmar um grande milagre como o de Ourique porque a imagem de D. Afonso Henriques «fabricando naquele memorável dia o Ceptro Português, e segurando a sua perpetuidade na prodigiosa visão de Cristo Senhor Nosso" $\left({ }^{14}\right)$ o põe fora de qualquer dúvida. Mas o mesmo não acontece quando, em outros casos, Caetano de Sousa afirma sem mais se pronunciar nem se comprometer "o que todos tiveram por milagre» e, quanto aos sebastianistas, acusa-os pura e simplesmente de "delírio da imaginação».

Pensamos que o que melhor define a História Genealógica da Casa Real Portuguesa é ser o "espelho do rei», ela diz-lhe não aquilo que ele deve ser, mas aquilo que ele $e$, que ele realmente é. A História Genealógica não quer educar o rei (embora considere importante a educação do príncipe), quer devolver-lhe a sua imagem. Esta imagem do Rei é construída com as "virtudes» e com a "prudência», prudência que tem exactamente o mesmo significado que "política» (empregue no sentido de realismo e pragmatismo político).

Os Reis são santos (Santo é D. Afonso Henriques mas também os outros, a santidade é-lhes intrínseca e inerente), pios, bravos, o seu aspecto físico é sempre descrito e, seja qual for o seu tipo, é sempre magestático. Veja-se por exemplo D. João I: ele é "valoroso», "sábio», "pio», "clemente», «liberal» e "político» ou "prudente». Teve um valido "grande em política» - o Doutor João das Regras - e com todas as suas virtudes e prudência "em tudo foi feliz o seu Reinado» $\left({ }^{15}\right)$. Quanto ao que não esteve bem nas suas decisões foi "mais efeito da política dos Ministros, do que do seu Real ânimo" $\left.{ }^{16}\right)$ - D. João I, como D. Sancho II ou D. Afonso IV, como todos os Reis, é inocente, a culpa é sempre dos "maus conselheiros» e validos, a inocência é também intrínseca e inerente ao Rei.

De D. João II diz António Caetano de Sousa que «mereceu ser chamado por antonomásia o Príncipe Perfeito. Tantas foram as virtudes, com que se soube adornar!» $\left({ }^{17}\right)$. E, com sensível prazer, traça o seu perfil psicológico e constrói-lhe a sua imagem $\left({ }^{18}\right)$ : de "coração impávido" e "entendimento superior», "grande memória» e "eloquente», "na filosofia, e na História era bem instruído, e estimava a

(14) António Caetano de Sousa, ob. cit., tomo I, p. 31.

(15) Ibidem, tomo II, p. 8.

(16) Ibidem, t. II, p. 13. .

(17) Ibidem, t. III, p. 63.

(18) Cf. ibidem, t. III, pp. 79, 67, 70. 
Poesia»; "generoso», «resoluto», "alegre», "grave e prudente», "estimou muito o segredo, e não menos os Ministros, ainda que com alguma desconfiança. Amou a Justiça, não faltando à piedade». Admira a "grandeza do seu ânimo real» e "é certo, que foi admirável a prudência, valor, e cautela, com que este grande Rei se portou com os amigos e inimigos, conservando a paz,.... porque no seu tempo se não atreveu ninguém a ofender os seus Vassalos». "No seu reinado foram com severidade guardadas as Leis, desterrando abusos, tirando aos Vassalos aquela autoridade, que arrogavam a si própria, e devida só à soberania». Em D. João II se exemplifica ainda uma outra face da essência do Rei: ele é também mártir. "Teve El-Rei por empresa um Pelicano ferindo o peito com o bico, com esta letra: Pela ley, e pela grey: Pro lege, e pro Grege: dizendo, que pela Religião, e por amor do seu Povo ele exporia a própria vida, pelos interesses de um, e pela defesa de outro" ( $\left.{ }^{19}\right)$. Mártir é também D. João IV, que depois de tanto evitar ser Rei acabou por aceitar a Coroa, "antepondo a saúde da Pátria ao risco particular» $\left({ }^{20}\right)$ e devotando-se em absoluto à "vigilância, cuidado, e política, com que procurava o maior bem do Reino» $\left({ }^{21}\right)$.

D. Manuel não foi «menos ornado de virtudes, do que favorecido de fortuna; porque foi liberal, magnífico, e favorecedor» $\left({ }^{22}\right)$ e D. João III de "olhos azuis escuros, mas alegres, e cheios de tanta magestade, e com um tão real aspecto, que se perturbavam os que não eram costumados a falar com ele» $\left({ }^{23}\right)$.

D. Sebastião é o exemplo do Rei com «virtudes» mas sem "prudência». "Foi El-Rei D. Sebastião de mediana estatura, branco, e louro, olhos azuis, de aspecto magestoso, com admirável proporção de partes, de espíritos verdadeiramente reais, porque nada viu de que se admirasse, coração ousado, e destemido, com tantas forças, que o fizeram temerário, e nos exercícios violentos excedia a todos na bizarria $\left({ }^{24}\right)$ de obrar assim a pé, como a cavalo» $\left.{ }^{25}\right)$. Mas D. Sebastião

(19) Ibidem, t. III, p. 85.

(20) Ibidem, t. VII, p. 42.

(21) Ibidem, t. VII, p. 132; Cf. Walter Benjamim, ob. cit., p. 71: «....c'est qu'il est la victime d'un déséquilibre entre la grandeur infinie dont le souverain est investi par Dieu et la misère de sa condition humaine".

(22) Ibidem, t. III, p. 109.

(23) Ibidem, t. III, p. 290.

(24) Para o significado coevo de «bizarria» cf. Vocabulário Por-

tuguez, e Latino de Raphael Bluteau.

(25) António Caetano de Sousa, ob. cit., t. III, p. 353. 
"perdeu-se a si, e ao Reino", "para o que concorreu ter um ânimo voluntário, e desprezador do conselho dos seus prudentes Ministros, sem os quais de ordinário são mui duvidosos nos Príncipes os acertos das resoluções públicas» $\left({ }^{26}\right)$ sobretudo quando o Rei não é, ele próprio, um "político» ( «desprezador dos conselhos dos Ministros» foi também D. Fernando). Este espírito "ambicioso de glória» de D. Sebastião era "fomentado da lisonja dos Validos, e Cortesãos» a quem cabe culpa. Verificamos assim que a "prudência» ou "política" é indispensável à composição da figura do Rei, mas não constitui a sua essência.

Depois do Cardeal D. Henrique, António Caetano de Sousa não se refere ao período filipino e concentra-se na legitimação da Casa de Bragança. Esta legitimação fá-la através da Genealogia e da identificação entre aparência e essência. A Sereníssima Casa de Bragança "subiu ao Trono Lusitano, revivendo nele a varonia dos Reis de Portugal, em que teve satisfação aquela infalível promessa de Cristo Senhor Nosso ao Invicto Rei D. Afonso I no Campo de Ourique, para que depois na descendência de seu sétimo neto, outro Afonso, se visse o cumprimento daquela profecia, e se estabelecesse a Monarquia na sua descendência. com a observância das Leis mais importantes, como são as Cortes de Lamego, para que assim fosse perpétua a gloriosa descendência daquele Santo Rei, continuando-se a sua varonia nos Duques de Bragança, que tiveram princípio na maneira seguinte. O Senhor D. Afonso, único do nome primeiro Duque de Bragança, foi filho del-Rei D. João o I....» $\left.{ }^{27}\right)$. É visível a importância fundamental da Genealogia.

O casamento deste primeiro Duque de Bragança já «foi em tudo Real", mas António Caetano de Sousa vai dedicar um capítulo exclusivamente às "Excelências, e Glórias da Sereníssima Casa de Bragança» ${ }^{28}$ ) porque "em tudo foi singular a Casa de Bragança, a qual em todo o tempo pareceu Real.... E assim brilhou nela sempre o respeito com uma tal semelhança de soberania». Os Duques conferiam a nobreza, conferiam quarenta e uma comendas na Ordem de Cristo. serviam-se de muitos fidalgos ilustres deste reino. "O modo com que se serviram os Duques, em tudo pareceu Real...., de sorte, que em tudo era servido com tal soberania, que não só mostrava grandeza no respeito, mas parecia

(26) Ibidem, t. III, pp. 346-347.

(27) Ibidem, t. V, p. 3.

(28) Cf. ibidem, t. VI, cap. XX. 
Real no aparato, e magnificência....; de maneira, que, ou fosse para o espiritual, ou para o decoro da grandeza, em tudo foram únicos aqueles Príncipes: este era o estilo, que a Casa de Bragança praticava tão conforme à Real, que excedia a alguns Soberanos no aparato, e magnificência». A essência real é assim imanente à aparência real, inscreve-se nela (conformemente ao princípio barroco da indissociabilidade da essência e da aparência).

Em 1683 houve tumultos em Vila Viçosa que aclamavam ao Duque D. João Rei de Portugal. "O Duque, que se achava impossibilitado com uma grave enfermidade, para poder sossegar aquele rumor com o acordo, que pedia negócio, em que se interessava a sua pessoa, e Casa, mandou na mesma noite sair pelas ruas ao Duque de Barcelos seu filho, que não tendo mais, que quatro anos, resplandeceram nele as luzes das suas virtudes, de que depois se ornou este excelente Príncipe, e com a sua presença compôs o rumor do povo; e se recolheu ao Paço, deixando tudo sossegado, e a seu pai livre do cuidado, que lhe havia causado o tumulto" $\left({ }^{29}\right)$. Do aglomerado de pequenos factos, enumeração de virtudes, narração de acções, descrições do aspecto físico, sai a Magestade como uma força. António Caetano de Sousa consegue dar a ver o infigurável, aquilo que vai para além do narrado e do representável. Ele mostra a Magestade como "luz», que "resplandece» já aos quatro anos de idade, luz que cai sobre o "povo" como uma chuva de ouro, luz da glória, luz do poder. A propósito de D. Pedro II, mas também para todos os reis, diz António Caetano de Sousa: «.....com aspecto tão magestoso, que a sua pessoa, vista entre outras, não podia entrar em dúvida que era Real, pela magestade da presença» $\left({ }^{30}\right)$. Resultante das "virtudes» e da "prudência» mas sobre elas, brilha a Magestade como a essência do Rei: "dos Ceptros, e das Coroas é inseparável a Magestade» $\left({ }^{31}\right)$. Signo da Magestade, o "sublime talento» ou o "sublime espírito" do Rei são expressões em que a palavra sublime significa o infinito, o sem-medida, a desmesura. A qualificação de sublime (constantemente repetida para D. Joẫo V) vem a par de outras como «inexplicável» ou «ânimo incomparável». No Palácio-Convento de Mafra "tudo está mostrando a incomparável grandeza do seu Fundador, cujo Real ânimo excede a toda a comparação» $\left({ }^{32}\right)$. D. João V, entre outras

(29) Ibidem, t. VII, pp. 27-28, sublinhado nosso.

( ${ }^{30}$ Ibidem, t. VII, pp. 372-373.

(31) Ibidem, t. III, p. 345.

(32) Ibidem, t. VIII, p. 137. 
ciências, teve particular gosto pela Matemática e a observação astronómica, dizendo António Caetano de Sousa que "humanando-se» chegou a ser ele mesmo, levado da curiosidade, quem com as suas Reais mãos ajustou os instrumentos para as observações» $\left.{ }^{33}\right)$.

Vítor Manuel de Aguiar e Silva pensa que na poesia e na arte barroca o realismo "conjuga-se» e "funde-se» continuamente com a construção de uma "sobrerrealidade». «Tal sobrerrealidade.... é instaurada pela energia ludicamente criadora do engenho, o qual.... transforma a linguagem.... num instrumento de transfiguração e reinvenção contínuas da realidade» $\left({ }^{34}\right)$. O mesmo podemos nós dizer para António Caetano de Sousa acentuando bem que é sobre o realismo que essa "sobrerrealidade» é construída. A História Genealógica inclui tudo: a importância e protecção dada ao comércio e à "economia do Reino", a construção de edifícios sumptuosos, de fábricas, de estradas, a atenção dada às ciências e às artes, leis, viagens, decisões políticas e militares, vida na Corte, porque "Em tudo se admira a sua [do Rei] Real magnificência» e também porque todas estas acções "pelo seu favor servem de grande utilidade aos seus Vassalos» $\left({ }^{35}\right)$.

Concluindo, D. João V «é superior a toda a grandeza humana naturalmente» $\left.{ }^{36}\right)$.

De interesse é também a análise da imagem do cortesão que António Caetano de Sousa constrói. O cortesão possui o "zelo de Vassalo", o "amor de Criado", a «fidelidade» e o "desinteresse» e ao mesmo tempo a "autoridade da experiência».

Os cortesãos e ministros são: "forjadores de máquinas», "políticos talentosos» e "mártires", como as três faces da mesma imagem. Eles são "políticos» e António Caetano de Sousa mostra uma nítida simpatia pela "política», embora considerando a ambiguidade dos políticos, sem verdade e sem moral, desprovidos de escrúpulos mas também servidores leais, companheiros do sofrimento do Rei.

Exemplo desta imagem do cortesão é o Conde de Castelo-Melhor, entre muitos e muitos outros. Ele é o Ministro que «forja máquinas» mas também o "Ministro cheio de zelo, vigilância, e com admirável capacidade» $\left({ }^{37}\right)$ e que no entanto

(33) Ibidem, t. VIII, p. 149, sublinhado nosso.

(34) Vítor Manuel de Aguiar e Silva, ob. cit., pp. 432-433.

(35) Ibidem, t. VIII, pp. 144 e 143.

(36) Ibidem, t. VIII, p. 177.

(37) Ibidem, t. VII, p. 212. 


\section{A imagem do Rei}

abandonou o governo quando "com resolução admirável, e a todas as luzes grande, se determinou a sacrificar os interesses próprios pela saúde da Pátria» $\left({ }^{38}\right)$.

$\mathrm{Na}$ intersecção das imagens dos reis surge a Imagem Real: Santo, Inocente, Mártir, Magestático. «Le souverain est le représentant de l'histoire. Il tient le cours de l'histoire dans sa main comme un sceptre» $\left({ }^{39}\right)$.

(38) Ibidem, t. VII, p. 257.

(39) Walter Benjamim, ob. cit., p. 65. Cf. tomo VIII da História Genealógica, p. 4: «....vendo agora o Príncipe Dom João.... segurando com a sua Real pessoa o Império Lusitano, na continuação da antiga varonia de seus Augustos progenitores....». 